OPEN ACCESS

Edited by:

Abhijeet Anil Bakre,

University of Georgia, United States

Reviewed by:

Rong Hai,

University of California, Riverside,

United States

Michael Schotsaert,

Icahn School of Medicine at Mount

Sinai, United States

*Correspondence:

Veronika von Messling

veronika.vonmessling@bmbf.bund.de

Specialty section:

This article was submitted to

Vaccines and Molecular Therapeutics,

a section of the journal

Frontiers in Immunology

Received: 31 October 2018

Accepted: 30 April 2019

Published: 05 June 2019

Citation:

Enkirch T, Sauber S, Anderson DE,

Gan ES, Kenanov D, Maurer-Stroh S and von Messling V (2019)

Identification and in vivo Efficacy

Assessment of Approved Orally Bioavailable Human Host

Protein-Targeting Drugs With Broad

Anti-influenza A Activity.

Front. Immunol. 10:1097.

doi: 10.3389/fimmu.2019.01097

\section{Identification and in vivo Efficacy Assessment of Approved Orally Bioavailable Human Host Protein-Targeting Drugs With Broad Anti-influenza A Activity}

\author{
Theresa Enkirch ${ }^{1,2}$, Svenja Sauber ${ }^{2}$, Danielle E. Anderson ${ }^{1}$, Esther S. Gan ${ }^{1}$, \\ Dimitar Kenanov ${ }^{3}$, Sebastian Maurer-Stroh ${ }^{3,4}$ and Veronika von Messling ${ }^{1,2 *}$ \\ ${ }^{1}$ Programme in Emerging Infectious Diseases, Duke-NUS Medical School, Singapore, Singapore, ${ }^{2}$ Veterinary Medicine \\ Division, Paul-Ehrlich-Institut, Langen, Germany, ${ }^{3}$ Biomolecular Function Discovery Division, Bioinformatics Institute, Agency \\ for Science, Technology and Research, Singapore, Singapore, ${ }^{4}$ Department of Biological Sciences, National University of \\ Singapore, Singapore, Singapore
}

The high genetic variability of influenza A viruses poses a continual challenge to seasonal and pandemic vaccine development, leaving antiviral drugs as the first line of defense against antigenically different strains or new subtypes. As resistance against drugs targeting viral proteins emerges rapidly, we assessed the antiviral activity of already approved drugs that target cellular proteins involved in the viral life cycle and were orally bioavailable. Out of 15 candidate compounds, four were able to inhibit infection by 10- to 100-fold without causing toxicity, in vitro. Two of the drugs, dextromethorphan and ketotifen, displayed a $50 \%$ effective dose between 5 and $50 \mu \mathrm{M}$, not only for the classic H1N1 PR8 strain, but also for a pandemic H1N1 and a seasonal H3N2 strain. Efficacy assessment in mice revealed that dextromethorphan consistently resulted in a significant reduction of viral lung titers and also enhanced the efficacy of oseltamivir. Dextromethorphan treatment of ferrets infected with a pandemic $\mathrm{H} 1 \mathrm{~N} 1$ strain led to a reduction in clinical disease severity, but no effect on viral titer was observed. In addition to identifying dextromethorphan as a potential influenza treatment option, our study illustrates the feasibility of a bioinformatics-driven rational approach for repurposing approved drugs against infectious diseases.

Keywords: influenza A virus, drug repurposing, antiviral (H1N1 and H3N2) activity, animal models, host proteintargeting drugs

\section{INTRODUCTION}

Influenza A viruses are one of the most important respiratory pathogens. Annual epidemics represent an important disease burden and cause an estimated 250,000-500,000 deaths worldwide, and occasional pandemics are associated with increased morbidity and mortality $(1,2)$. Influenza A viruses belong to the Orthomyxoviridae family and have a segmented negative-sense RNA genome (3). Their envelope contains the ion channel forming M2 protein and the hemagglutinin (HA), and neuraminidase (NA) glycoproteins. Based on the antigenic properties of these viral glycoproteins, influenza A viruses are classified into different subtypes. To date, 18 hemagglutinin (H1-H18) and 11 neuraminidase (N1-N11) subtypes have been identified $(3,4)$. 
With the exception of bat-associated subtypes (4), all influenza A virus subtypes can be found in wild aquatic birds, which are their natural reservoir. From these animals the virus can spread to domestic poultry or directly to humans and other mammalian hosts (5). Pandemics occur if such a new subtype acquires the ability to infect and transmit in the human population. Over the last 20 years, there have been regular introductions of $\mathrm{H} 5 \mathrm{~N} 1$ strains and occasional cases of $\mathrm{H} 7 \mathrm{~N} 1$ and H9N2 infections, mostly associated with outbreaks in poultry $(6,7)$. Since March 2013, human infections with a previously undescribed H7N9 virus were observed, which also circulates in domestic birds without causing severe disease (8). Even though the production of influenza vaccines is well established, and the regulatory process allows for rapid strain update or exchange, it takes 4-6 months until a vaccine against a newly emerging subtype is available in sufficient quantities $(2,9)$.

Thus, antiviral drugs are an essential component of pandemic response scenarios and play an important role in reducing disease severity during seasonal influenza epidemics. Two classes of approved drugs against influenza A virus infections have been available for years: adamantane-based M2 ion channel blockers, which prevent acidification of the endosome and therefore release of the viral particles into the cytosol (10), and neuraminidase inhibitors, which prevent the release of newly formed viral particles from infected cells (11). In both cases, resistant viruses emerged rapidly after the onset of widespread use, and at this time, all circulating human influenza A viruses are adamantane-resistant (12), and the number of neuraminidase inhibitor-resistant viruses is rapidly increasing (13). Earlier this year, baloxavir marboxil, a cap-dependent endonuclease inhibitor, has been licensed in Japan for the treatment of influenza virus infections (14), and favipiravir, an inhibitor of the RNA-dependent RNA polymerase, is in advanced clinical development stages (15), so additional treatment options are becoming available. Repurposed drugs targeting cellular instead of viral proteins are considered a promising complement, on the one hand because of the potential for efficacy against a broader range of viruses using the respective pathway, and on the other hand due to the reduced probability for acquisition of resistance-conferring mutations without fitness cost $(16,17)$.

Whole genome siRNA screens have yielded a list of promising candidate proteins and pathways involved in the influenza virus life cycle (18-21). Watanabe et al. previously described a network of 128 consensus human host genes that were identified in at least 2 separate of these experimental screens to be important for the virus life cycle in the host cell (22). In this study, we re-analyzed the network of consensus cellular candidate proteins from these screens and overlapped it with databases of known cellular targets of already licensed drugs, which would thus be immediately available in case of a pandemic. The anti-influenza activity of the top candidates was then first evaluated in vitro, followed by an efficacy assessment of the most promising drugs in mice and ferrets.

\section{MATERIALS AND METHODS}

\section{Cells and Viruses}

Madin-Darby canine kidney (MDCK) cells (ATCC CCL-34) cells were maintained in Dulbecco's modified eagle medium (DMEM) supplemented with $5 \%$ fetal calf serum (FCS), and $1 \%$ Lglutamine at $37^{\circ} \mathrm{C}$. The influenza A virus strains H1N1 A/Puerto Rico/8/34 (PR8, (23), H3N2 A/Victoria/36/2011 (H3N2, kind gift from Ralf Wagner, Paul-Ehrlich-Institut), and H1N1 pdm09A/Mexico/InDRE4487/2009 [H1N1pdm09, (24)] were propagated in MDCK cells cultivated in DMEM supplemented with $0.75 \mu \mathrm{g} / \mathrm{ml}$ tolylsulfonyl-phenylalanyl-chloromethyl-ketone (TPCK)-trypsin (Sigma) at $37^{\circ} \mathrm{C}$. After $12-24 \mathrm{~h}$, the viruscontaining supernatant was harvested, centrifuged at $4^{\circ} \mathrm{C}$ for $5 \mathrm{~min}$ at $800 \mathrm{~g}$ to remove cell debris, aliquoted, and stored at $-80^{\circ} \mathrm{C}$. Virus titers were determined by limited-dilution method and expressed as 50\% tissue culture infectious doses per $\mathrm{ml}\left(\mathrm{TCID}_{50} / \mathrm{ml}\right)$.

\section{Bioinformatics Analysis}

Watanabe et al. previously described a network of 128 consensus human host genes that were identified in at least two separate experimental screens to be important for the virus life cycle in the host cell (22). The 128 gene nodes from this network were originally connected by 431 edges, which constituted the basis for our analysis. We re-analyzed the network and added new edges from co-expression and protein-protein interaction data. For the co-expression, 62 human microarray datasets from NCBI GEO (25) with minimum 25 samples available (to limit to larger studies) were used to search for correlations between pairs of genes. For a given gene, the Pearson correlation coefficient (PCC) is calculated for every other gene over the 62 datasets. PCC $>0.5$ or smaller than -0.5 was considered for establishing 4,482 co-expression links between gene pairs. Five hundred and seventy-four protein-protein interaction links were derived from our in-house integrated protein interaction database, which is a collection of experimentally determined protein-protein interactions and contains data from 10 publicly available resources (26). 319 virus and gene/protein interactions were retained from the network of 128 consensus human host genes (22). A Perl script was written to format the nodes and edges for GraphViz Version 2.38 [http://www.graphviz.org] and the network drawn with layout from the NEATO springbased algorithm [http://www.graphviz.org/pdf/neatoguide.pdf]. 14 gene targets of FDA-approved drugs were identified among the 128 nodes by a custom Perl script that identifies direct as well as alternative gene name matches in the DrugBank flat file version 3.0 (27). Fifteen drugs were selected based on oral bioavailability as well as different degrees of connectivity of the respective target genes in our network, price, and low organism toxicity.

\section{In vitro Influenza Virus Inhibition Assays}

All compounds were purchased from Sigma and diluted in either water, phosphate buffer saline (PBS), or dimethyl sulfoxide (DMSO, Sigma) to stock concentrations of $0.5 \mathrm{M}$, and DMEM was used for all further dilutions. For the initial efficacy screen, 
12-well plates seeded with MDCK cells were pretreated with the respective compound for $8 \mathrm{~h}$ with 50 or $500 \mu \mathrm{M}$ of each compound. The cells were then washed with PBS, infected with the PR8 at an MOI of 0.01, and cultivated in TPCK-DMEM $(0.75 \mu \mathrm{g} / \mathrm{ml})$ containing the same drug concentration. Sixteen hour post-infection, the supernatant was stored at $-80^{\circ} \mathrm{C}$, and the amount of virus was quantified by limited dilution method and expressed as $50 \%$ tissue culture infectious dose $\left(\right.$ TCID $\left._{50}\right)$. To evaluate the inhibitory effect of the lead compounds in more detail, the experiment was repeated including additional drug concentrations and different influenza A strains.

For the calculation of the $50 \%$ effective concentration $\left(\mathrm{EC}_{50}\right)$, a modified plaque reduction assay was used (28). Briefly, MDCK cells were seeded in 6-well plates and pretreated for $8 \mathrm{~h}$ with the drug of interest at 5 -fold decreasing doses. The cells were then infected with the respective virus at a dose that yields 15-45 plaques per well in the absence of treatment. After incubation for $1 \mathrm{~h}$ at $37^{\circ} \mathrm{C}$, the cells were washed with PBS, and overlayed with avicel (Sigma) containing the respective drug concentration. After 3 days, the overlay was removed and the wells were stained with $1 \%$ crystal violet solution (Sigma), and plaques were counted. GraphPad 6 was used for curve fitting and $\mathrm{EC}_{50}$ calculation.

\section{MTT Assay}

The MTT assay was performed according to the manufacturer's protocol (Thermo Fisher Vybrant MTT Cell Proliferation Assay Kit). Briefly, MDCK cells grown in a 96-well-plate were treated with the respective drugs at 5 -fold descending concentrations starting at $500 \mathrm{mM}$ or left untreated. After $24 \mathrm{~h}$, medium was replaced by PBS containing $1 \mathrm{mM}$ MTT. After incubation for $4 \mathrm{~h}$ at $37^{\circ} \mathrm{C}$, supernatants were removed, mixed with DMSO and further incubated for $10 \mathrm{~min}$ at $37^{\circ} \mathrm{C}$ before absorption was measured at $562 \mathrm{~nm}$ using a PHOmo Microplate reader. To calculate the relative cytotoxicity, the absorbance of untreated cells was set to 1 . The $50 \%$ cytotoxic concentration $\left(\mathrm{CC}_{50}\right)$ was calculated using GraphPad 6, and the selectivity index (SI) represents the ratio of $\mathrm{CC}_{50}$ to $\mathrm{EC}_{50}$.

\section{In vivo Efficacy Assessments}

All animal experiments were reviewed and approved by the SingHealth IACUC Committee or the German competent authority (Regierungspraesidium Darmstadt) and carried out according to Singaporean or German Animal Welfare Law, respectively. Groups of 4-6 week-old female C57BL/6 mice (Janvier Labs) were anesthetized by intraperitoneal injection of ketamine/xylazine $(100 / 5 \mathrm{mg} / \mathrm{kg})$, followed by intranasal infection with $1 \times 10^{3} \mathrm{TCID}_{50}$ of PR8 in $30 \mu \mathrm{l}$ of DMEM. Based on the tolerated doses published for the respective drug (29), a dose-finding study was performed, resulting in the following doses used in all mouse experiments: $50 \mathrm{mg} / \mathrm{kg} /$ day for oseltamivir phosphate, $40 \mathrm{mg} / \mathrm{kg} /$ day for naltrexone, $100 \mathrm{mg} / \mathrm{kg} /$ day gallium nitrate, $80 \mathrm{mg} / \mathrm{kg} /$ day for ketotifen, and $60 \mathrm{mg} / \mathrm{kg} /$ day for dextromethorphan. Animals were gavaged once daily starting 1 day before infection. Three days after infection, the mice were sacrificed and the viral titer in the lungs was determined. Toward this, the lung was weighed and homogenized in $500 \mu \mathrm{l}$ DMEM with $3 \times$ concentrated penicillin/streptomycin using $2 \mathrm{ml}$ homogenizer tubes (Lysing matrix D, MP Biomedicals) and the Precellys 24-Dual Homogenizer (Peqlab). The titer in the supernatants was quantified by limited dilution method on MDCK cells and expressed as $\mathrm{TCID}_{50} / \mathrm{g}$.

To evaluate the treatment effect on disease severity in a more clinically relevant situation, groups of male, and female adult European ferrets (mustela putorius furo, bred in-house) without antibodies against circulating seasonal influenza A virus strains were treated orally every $8 \mathrm{~h}$ with either oseltamivir $(2.5 \mathrm{mg} / \mathrm{kg}$, Roche) or dextromethorphan (2 mg/kg, Procter, \& Gamble) following the manufacturer's dosing and treatment recommendation, starting $24 \mathrm{~h}$ before infection, or left untreated. For infection, animals were anesthetized with ketamine and medetomidine $(2 / 0.2 \mathrm{mg} / \mathrm{kg})$, and then inoculated intranasally with $1 \times 10^{5}$ TCID $_{50}$ H1N1pdm09. Treatment was continued

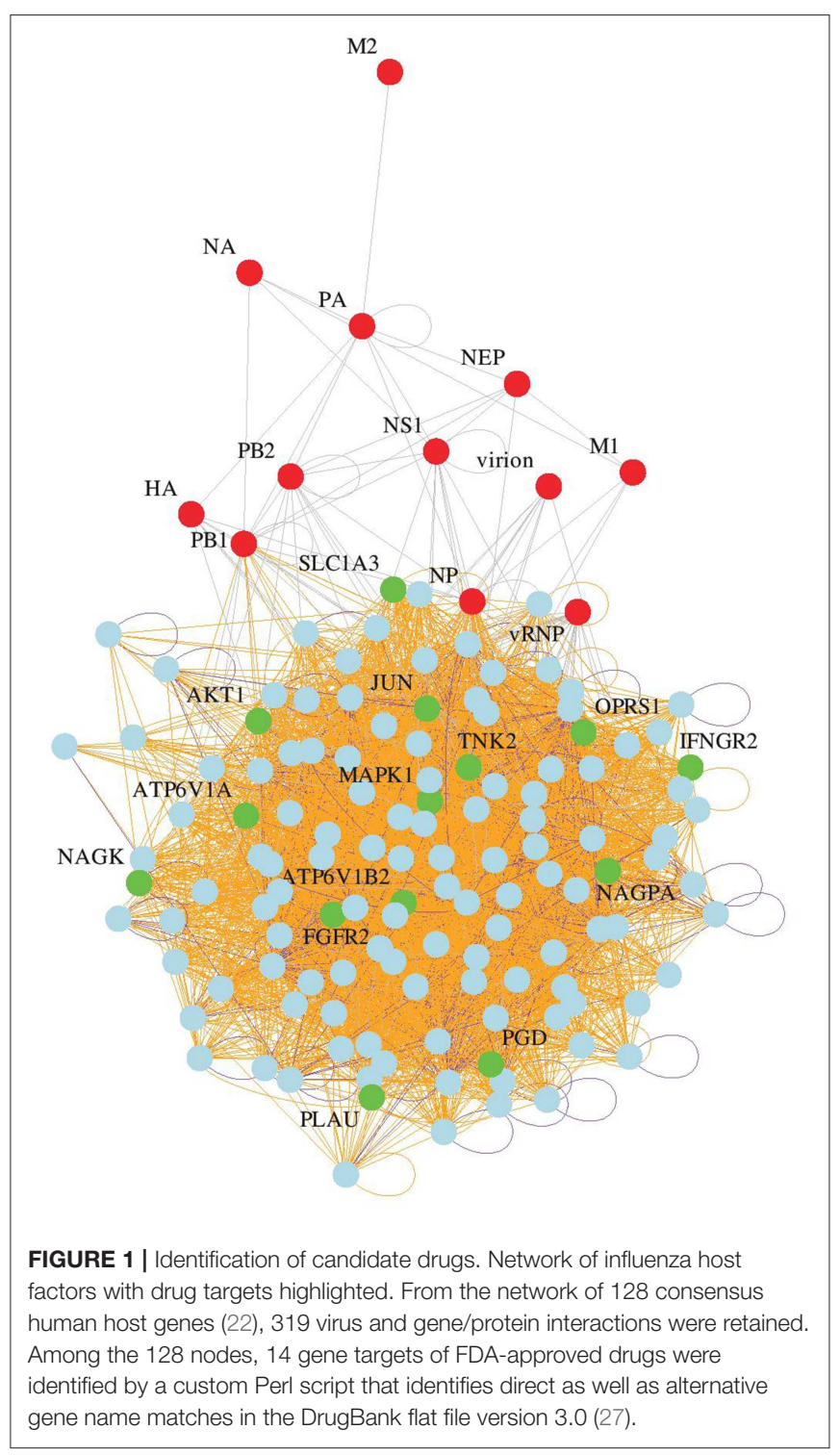


until day 4 post-infection. During that time, clinical signs, body temperature, and weight were assessed twice daily, and then daily until day 7. Respiratory signs, sneezing, nose exudates, congestion, and activity were scored using a 0-12 scale. Zero indicates minimal deviations of the physiologic state, 1 indicates moderate nasal discharge, congestion, and/or occasional sneezing, and calm demeanor, and 2 indicates severe nasal discharge and/or labored breathing, dyspnea, frequent sneezing, and depression. Nasal washes were collected every day for the first 4 days and on day 7. Toward this, $500 \mu \mathrm{l}$ of PBS was administered in one nostril and expectorate was collected in $50 \mathrm{ml}$ centrifuge tubes. This procedure was repeated twice to obtain a minimal volume of $400 \mu \mathrm{l}$. The virus titer of the nasal washes was determined by limited dilution method.

\section{Statistical Analyses}

Statistically significant differences between animal groups were determined using one-way analysis of variance (ANOVA) with Dunnett's Multiple Comparison Test for mice treatment group comparison and Tukey's Multiple Comparison Test for ferret clinical score comparison using GraphPad 6.

\section{RESULTS}

\section{Identification of Approved Drugs Targeting Cellular Proteins Involved in the Influenza Virus Life Cycle}

Whole genome siRNA screens using different influenza A virus strains and cell lines have yielded a list of cellular proteins that are required in the influenza virus life cycle (22). While it is in most cases unknown if these identified proteins are directly interacting with viral proteins, or if they act indirectly, drugs that modulate their expression levels or activity may also inhibit influenza virus. Therefore, we computationally searched for FDA-approved drugs annotated in DrugBank (27) to target any of the genes in our updated host factor network generated by a meta-analysis of available influenza virus siRNA screen data sets (Figure 1). This bioinformatics analysis yielded 23 candidates, of which 15 drugs linked to 14 different host genes were chosen for further characterization based on oral bioavailability, since this would be a prerequisite for widespread use during a severe epidemic or pandemic. In addition, price, low organism toxicity, commercial availability, and level of connectivity of the respective target genes in our network were also taken into consideration (Table 1).

\section{Four of the Identified Compounds Inhibit Influenza A Virus Replication}

To identify candidates with influenza virus inhibitory activity, cells were pre-treated with the respective drug at 50 and $500 \mu \mathrm{M}$, and virus titers were quantified $16 \mathrm{~h}$ after infection with PR8, which corresponded to the peak titer in the untreated samples. Four of the compounds, isoproterenol, alendronate, vinblastine, and irbesartan, displayed pronounced toxicity at the $500 \mu \mathrm{M}$ concentration, and no antiviral activity at a 10 -fold lower concentration (Table 1). Adenosine triphosphate, etidronic acid, N-acetyl-D-glucosamine, L-glutamic acid, thalidomide, amiloride, and dacarbazine had no antiviral activity (Table 1).

TABLE 1 | Inhibition of influenza A virus replication by licensed drugs with Drug ID and cellular targets identified by bioinformatics analysis.

\begin{tabular}{|c|c|c|c|}
\hline Drug Candidate & Drugbank ID & Annotated Target & Inhibitory effect \\
\hline Arsenic trioxide & DB01169 & AKT1, JUN, MAPK1 & Excluded; high organism toxicity \\
\hline Tiludronate & DB01133 & ATP6V1A & Excluded; no oral administration \\
\hline Palifermin & DB00039 & FGFR2 & Excluded; no oral administration \\
\hline Interferon gamma-1b & DB00033 & IFNGR2 & Excluded; no oral administration; costly \\
\hline Pentazocine & DB00652 & OPRS1 & Excluded; controlled substance \\
\hline Remoxipride & DB00409 & OPRS1 & Excluded; no longer licensed \\
\hline Gadopentetate dimeglumine & DB00789 & PGD & Excluded; no oral administration \\
\hline Urokinase & DB00013 & PLAU & Excluded; no oral administration \\
\hline Isoproterenol & DB01064 & MAPK1 & toxic \\
\hline Alendronate & DB00630 & ATP6V1A & toxic \\
\hline Vinblastine & DB00570 & JUN & toxic \\
\hline Irbesartan & DB01029 & JUN & toxic \\
\hline Adenosine triphosphate & DB00171 & AKT1,TNK2 & No inhibition \\
\hline Etidronic Acid & DB01077 & ATP6V1A & No inhibition \\
\hline N-Acetyl-D-Glucosamine & DB00141 & NAGK, NAGPA & No inhibition \\
\hline L-Glutamic Acid & DB00142 & SLC1A3 & No inhibition \\
\hline Thalidomide & DB01041 & FGFR2 & No inhibition \\
\hline Amiloride & DB00594 & PLAU & No inhibition \\
\hline Dacarbazine & DB00851 & PGD & no inhibition \\
\hline Gallium nitrate & DB05260 & ATP6V1B2 & >10-fold inhibition \\
\hline Naltrexone & DB00704 & OPRS1 & >10-fold inhibition \\
\hline Dextromethorphan & DB00514 & OPRS1 & >10-fold inhibition \\
\hline Ketotifen & DB00920 & PGD & >10-fold inhibition \\
\hline
\end{tabular}




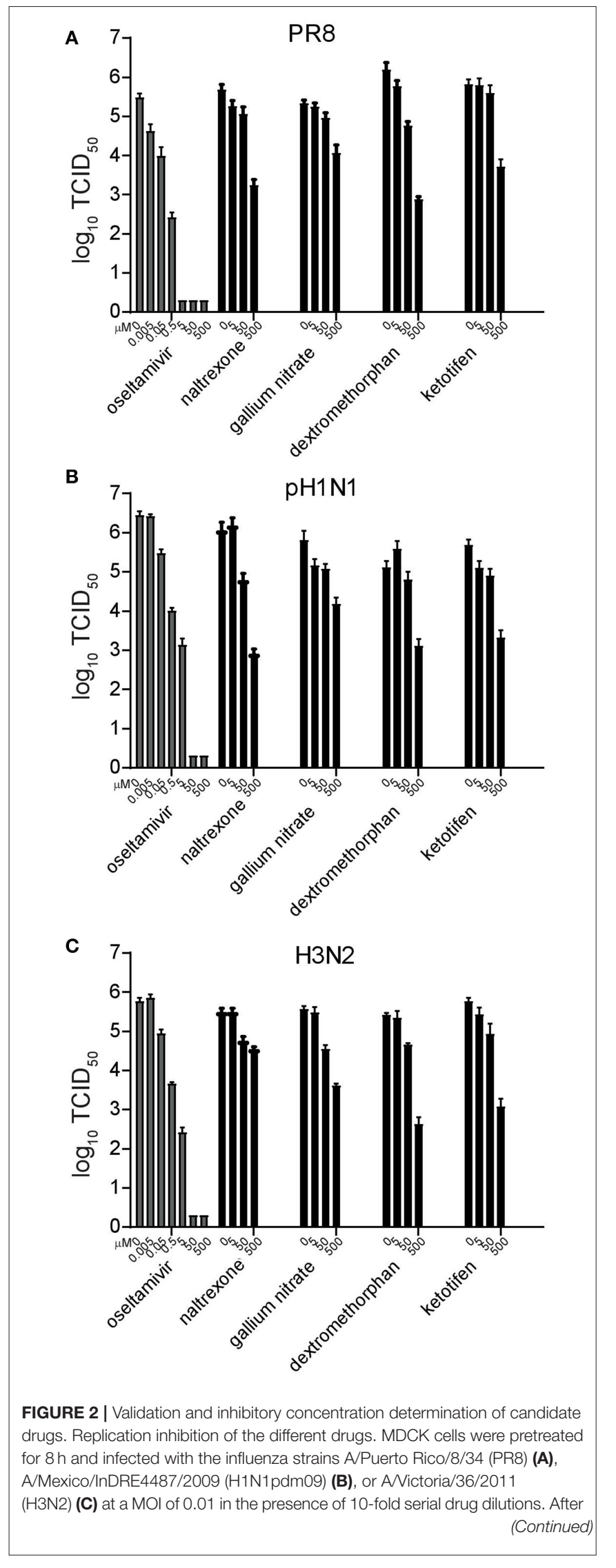

FIGURE 2 | $16 \mathrm{~h}$, the supernatant was harvested and the amount of virus quantified by limited dilution method. Bars represent the average of three independent duplicate experiments, and error bars indicate the standard deviation.

Thus, these 11 compounds were excluded from further evaluation. The four remaining compounds, gallium nitrate, naltrexone, dextromethorphan, and ketotifen, were able to inhibit infection at doses above $50 \mu \mathrm{M}$ without causing toxicity (Table 1). Gallium nitrate is used to treat cancerassociated hypercalcemia, since it prevents osteoclastic activity, by inhibiting ATPase-dependent proton pumps $(30,31)$. These pumps, including the vATPase (ATP6V1B2, Table 1) are also involved in acidification of the endosome, which may explain its inhibitory effect on influenza A viruses (32). Naltrexone, a competitive opioid receptor agonist which primarily targets $\mu$ - and to a lesser extent the $\kappa$-opioid receptors, and dextromethorphan, a $\sigma_{1}$-receptor, and $\mu$-opioid receptor agonist, can both act on the $\sigma_{1}$-receptor (OPRS1) (33). OPRS1 is involved in diverse intracellular processes (34), including the modulation of innate and adaptive immune responses (35), which may be the basis for its antiviral activity against influenza. Ketotifen, a histamine H1 receptor blocker (36), was found to block 6-phosphogluconate dehydrogenase (PGD) in vitro (37), which is upregulated in influenza A virus-infected cells (38).

To determine whether the antiviral activity of these four potential candidates extended to circulating seasonal H3N2 and pandemic H1N1 influenza strains, A/Victoria/36/2011 (H3N2), and A/Mexico/InDRE4487/2009 (H1N1pdm09) were included in the study. The neuraminidase inhibitor oseltamivir carboxylate was used as a positive control. Using the same experimental setup with 10 -fold decreasing drug concentrations starting at $500 \mu \mathrm{M}$, oseltamivir carboxylate completely inhibited replication of all three strains at concentrations higher than $5 \mu \mathrm{M}$ (Figure 2). In contrast, all four drugs targeting cellular proteins were only able to reduce viral titers starting at concentrations around $5 \mu \mathrm{M}$ (Figure 2). This effect ranged from around 10 -fold for gallium nitrate to 100 -fold for naltrexone and ketotifen, and around 1,000-fold for dextromethorphan. While the extent of inhibition varied for each of the viruses, this tendency was consistently observed, thereby validating our initial findings.

To calculate the $\mathrm{EC}_{50}$ for each drug against the different viruses, a more sensitive modified plaque assay was used, which assesses the percent plaque reduction at the respective drug concentration (28). Using 5-fold decreasing drug concentrations, again starting at $500 \mu \mathrm{M}$, the $\mathrm{EC}_{50}$ of oseltamivir carboxylate ranged between 5 and $200 \mathrm{nM}$, with PR8 being most effectively inhibited $\left(\mathrm{EC}_{50}\right.$ of $\left.5 \mathrm{nM}\right)$, while the $\mathrm{EC}_{50}$ for H1N1pdm09 was around $200 \mathrm{nM}$ (Table 2). Naltrexone inhibited both H1N1 viruses with an $\mathrm{EC}_{50}$ between 5 and $50 \mu \mathrm{M}$ but was less efficient against the $\mathrm{H} 3 \mathrm{~N} 2$ virus, whereas gallium nitrate, ketotifen, and dextromethorphan displayed $\mathrm{EC}_{50}$ between 5 and $50 \mu \mathrm{M}$ against all three viruses (Table 2). To determine 
TABLE 2 | Fifty percent cytotoxic concentration $\left(\mathrm{CC}_{50}\right)$ in MDCK cells, 50\% effective concentration (EC $\left.{ }_{50}\right)$ measured by modified plaque reduction assay, and the resulting selectivity index (SI) of the different compounds against $\mathrm{H} 1 \mathrm{~N} 1$ and $\mathrm{H} 3 \mathrm{~N} 2$ influenza $\mathrm{A}$ viruses.

\begin{tabular}{|c|c|c|c|c|c|c|c|}
\hline & \multirow[b]{2}{*}{$\mathrm{CC}_{50}(\mu \mathrm{M})$} & \multicolumn{2}{|c|}{ PR8 } & \multicolumn{2}{|c|}{ pH1N1 } & \multicolumn{2}{|c|}{ H3N2 } \\
\hline & & $E_{50}(\mu M)$ & SI & $E_{50}(\mu M)$ & SI & $E_{50}(\mu M)$ & SI \\
\hline Oseltamivir & $470 \pm 12.3$ & $0.005 \pm 0.0004$ & 94,000 & $0.2 \pm 0.05$ & 2350 & $0.05 \pm 0.003$ & 9,400 \\
\hline Naltrexone & $5233 \pm 227$ & $4.7 \pm 0.2$ & 1,113 & $48.0 \pm 3.2$ & 109 & $>500$ & n.d. \\
\hline Gallium nitrate & $716 \pm 116$ & $54.8 \pm 2.2$ & 13.1 & $55.3 \pm 2.9$ & 12.9 & $5.7 \pm 0.9$ & 126 \\
\hline Ketotifen & $291 \pm 14.8$ & $5.9 \pm 0.2$ & 49.3 & $33.7 \pm 1.3$ & 8.6 & $48.5 \pm 2.0$ & 6.0 \\
\hline Dextromethorphan & $3546 \pm 11.1$ & $48.7 \pm 2.3$ & 72.8 & $50.8 \pm 3.3$ & 69.8 & $51.7 \pm 4.2$ & 68.6 \\
\hline
\end{tabular}

the selectivity index (SI), the cytotoxic concentration for each of the drugs was determined in MDCK cells using an MTT assay. While the SI for oseltamivir carboxylate was between 2,000 and 100,000 , the SI for the drugs targeting cellular proteins ranged between 10 and 1000 with the SI of dextromethorphan being between 50 and 100 across different viruses (Table 2).

\section{Prophylactic Treatment With Ketotifen or Dextromethorphan Reduces Lung Titers in Mice}

To gain first insights in the ability of the four candidate drugs to reduce virus replication in vivo, C57BL/6 mice were treated orally once a day starting 1 day before infection with the respective drug. For all drugs, the initial doses were chosen based on published tolerated doses $(29,39-$ 41 ), and optimal concentrations were determined in an initial dose-finding study (data not shown). Comparison of lung virus titers at peak infection and survival curves revealed that statistically significant differences could be attained with smaller groups if lung virus titers were measured, since drug treatment delayed but did not completely prevent mortality (Supplemental Figure 1). Toward this, animals were infected intranasally with $10^{3}$ TCID $_{50}$ PR8, sacrificed 3 days postinfection, and the viral load in the lung was quantified. Oseltamivir phosphate was most effective, reducing lung titers 28 -fold, followed by dextromethorphan, which resulted in a more variable but significant reduction. Ketotifen was less effective, but still lowered lung viral titers around 8- to 10fold, while naltrexone and gallium nitrate treatments had no significant effect (Figure 3A).

As a $\sigma_{1}$-receptor agonist, dextromethorphan targets a different cellular pathway than ketotifen, which is a histamine $\mathrm{H} 1$ receptor blocker $(36,42)$. To evaluate potential additive effects of the two drugs and oseltamivir, mice were again treated orally once daily with the respective drug combinations, starting again 1 day before infection. In this series of experiments, the inhibitory effect of ketotifen alone was even less pronounced, and there was no additive effect when ketotifen and dextromethorphan were combined. Combination of each of the drugs with oseltamivir resulted in a slight, but non-significant increase in inhibition, but when all three drugs were combined, the inhibitory effect was significantly higher than that of oseltamivir alone (Figure 3B),

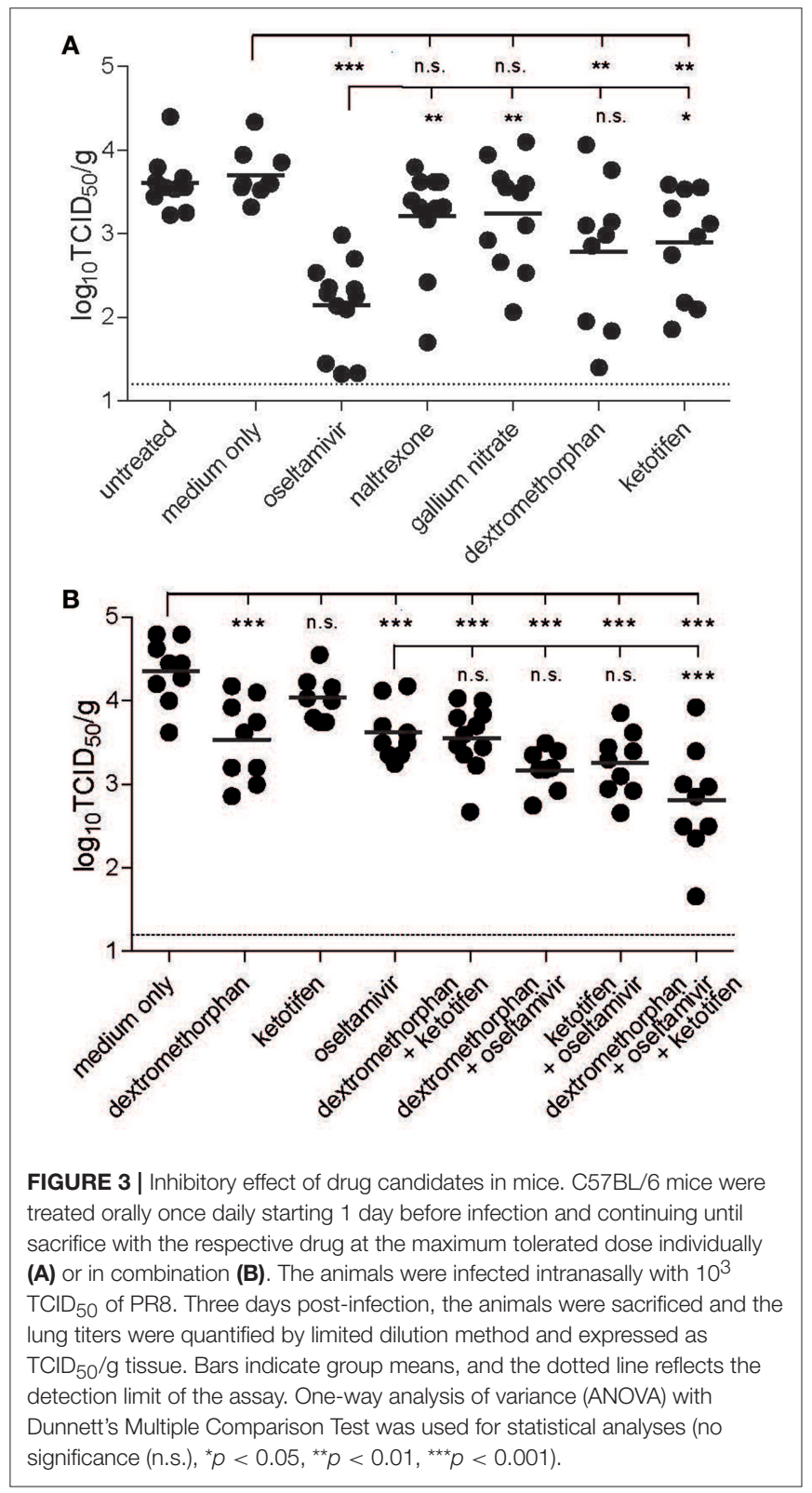

suggesting a modest benefit of combination treatment in this context. 

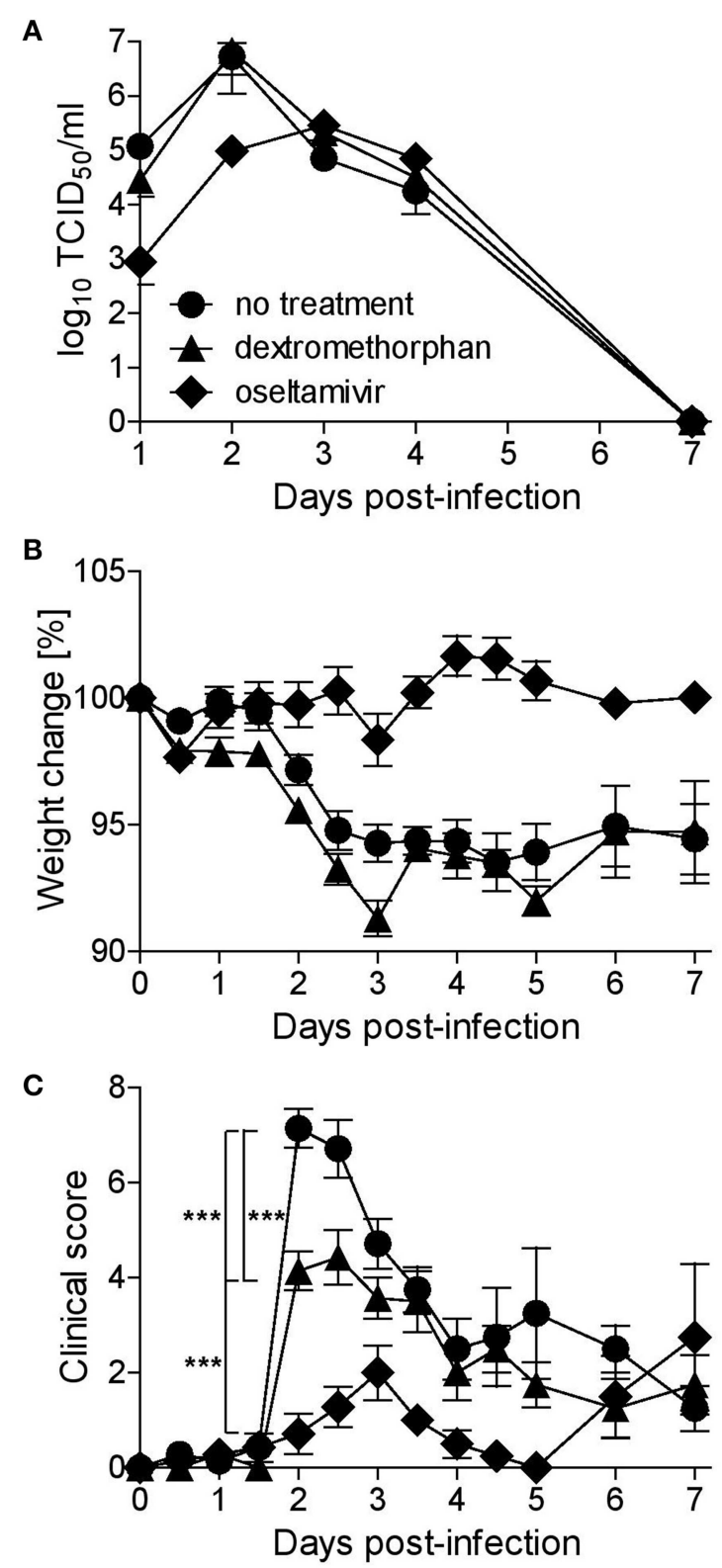

FIGURE 4 | Dextromethorphan efficacy assessment in ferrets. Ferrets $(n=9)$ were treated orally every $8 \mathrm{~h}$ for 5 days or until sacrifice on day $3(n=4)$, starting 1 day before infection with $2 \mathrm{mg} / \mathrm{kg}$ dextromethorphan or $2.5 \mathrm{mg} / \mathrm{kg}$ oseltamivir, corresponding to recommended human doses. The animals were infected intranasally with $10^{5} \mathrm{TCID}_{50}$ of A/Mexico/InDRE4487/2009. (A) Nasal washes were collected daily, and titers were quantified by limited dilution method. For the first 4 days, animals were monitored twice daily and daily thereafter for weight (B) and clinical signs (C). The clinical score represents a composite score of body temperature, activity, nasal exudate, and respiratory signs scored on a 0-1-2 scale with 0 representing body temperatures $\leq 39.3^{\circ} \mathrm{C}$ and the physiologic state, 1 temperatures $39.4-39.9^{\circ} \mathrm{C}$, calm behavior, low amounts of clear exudate, and occasional sneezing or congestion, and 2 temperatures $\geq 40.0^{\circ} \mathrm{C}$, depressed behavior, larger amounts of yellow or brown exudate, and frequent sneezing, coughing and/or dyspnea. Symbols represent group averages, and error bars indicate the standard error mean. One-way analysis of variance (ANOVA) with Tukey's Multiple Comparison Test was used for statistical analyses ( ${ }^{\star \star *} p<0.001$ ).

\section{Dextromethorphan Has no Effect on Viral Load but Reduces Clinical Disease in Ferrets}

To assess the therapeutic potential of dextromethorphan in an animal model that reproduces the course of disease seen in humans $(43,44)$, ferrets were treated every $8 \mathrm{~h}$ with either commercially available oral dextromethorphan formulation at a dose of $2 \mathrm{mg} / \mathrm{kg}$, or oseltamivir solution at a dose of $2.5 \mathrm{mg} / \mathrm{kg}$. This schedule was in accordance with the recommendation for dextromethorphan treatment of patients, and the doses were within the weight adjusted human dose range. Drugs were given for the first time $24 \mathrm{~h}$ prior to infection and treatment was continued for 5 days. Nasal washes were collected daily, and the animals were evaluated twice daily for weight loss, temperature, and clinical signs.

While oseltamivir phosphate treatment resulted in a 10fold reduction in nasal wash titers during the first 2 days, dextromethorphan had no effect (Figure 4A), and none of the treatment approaches affected lung viral titers in animals sacrificed on day 3 (data not shown). In all three groups, the titers peaked on day 2 post-infection and then gradually decreased (Figure 4A). Dextromethorphan-treated animals also experienced a similar gradual weight loss of $<10 \%$ seen in non-treated control animals, whereas there was no reduction in body weight in the oseltamivir group (Figure 4B). In the control group, clinical signs and fever became first apparent $36 \mathrm{~h}$ post-infection, peaked after $48 \mathrm{~h}$, and then gradually decreased (Figure 4C). Dextromethorphan treatment resulted in a significantly lower peak score (Figure $4 \mathrm{C}$ ). Even though the effect was less pronounced compared to oseltamivir phosphate treatment, which only resulted in a minimal clinical score peaking on day 3 (Figure 4C), it illustrates the potential of repurposing drugs targeting cellular factors involved in the viral life cycle.

\section{DISCUSSION}

Antiviral approaches targeting cellular proteins or pathways involved in the viral life cycle rather than viral proteins directly have great appeal as they are thought to be less prone to resistance development and may be effective against different strains and even different virus families $(16,45)$. For influenza virus, several whole genome siRNA screens have been published in recent years (18-21), allowing the cross-matching of host proteins required for influenza replication with known cellular drug targets. Using this approach, we identified a short list of 15 FDA-approved candidate drugs, of which naltrexone, gallium nitrate, ketotifen, and dextromethorphan were able to inhibit viral replication in vitro in a dose-dependent manner. Successive in vivo evaluation in mice revealed that dextromethorphan was the most promising candidate. Dextromethorphan treatment of ferrets infected with a H1N1pdm09 strain had no effect on viral load or body weight, but resulted in a significant reduction of clinical signs, supporting its further consideration as an influenza treatment option. 
High-throughput siRNA screens have opened a new avenue for drug repurposing (46). This is of special relevance for infectious disease targets with lesser market potential, as the development of new drugs is time consuming and costly $(47,48)$. The severe side effects associated with the chemotherapeutics and immune modulators often found among the top hits may not be acceptable in the context of the target disease, so they are usually not evaluated any further. In vitro efficacy assessments of the remaining hits are amenable to medium or high throughput screening, allowing a rapid identification of the most promising candidates (49). Here we show that an in vivo efficacy assessment of such candidates is warranted even if the $\mathrm{EC}_{50}$ is in the $\mu \mathrm{M}$ range and the SI is consequently low, especially if the drug has a broad therapeutic range, as they may be attractive options for treatment in combination with antivirals or other drugs targeting complementary cellular pathways involved in the viral life cycle.

Two of the identified drugs, ketotifen, and dextromethorphan, not only led to a reduction of viral titers in vitro, but also in mice. While ketotifen blocks histamine $\mathrm{H} 1$ receptors and the release of inflammatory mediators, and is used to treat asthma, rhinitis, skin allergies, and anaphylaxis (36, 50 ), dextromethorphan is primarily a $\sigma_{1}$-receptor agonist and used as an alternative to opioid-containing cough suppressants $(51,52)$. The antiviral properties of ketotifen may thus be associated with its anti-inflammatory effect (39), which could be substantiated by comparatively quantifying the release of inflammatory mediators in ketotifen- and untreated infected cells or animals. In contrast, the mechanism of action is less obvious for dextromethorphan. Its target, the $\sigma_{1}$-receptor, is a chaperone located at the mitochondria-associated endoplasmic reticulum (ER) membrane (53). The protein plays an important role in cell homeostasis, since its knock down leads to ER stress, induction of the unfolded-protein response (UPR), dysfunctional autophagosomes, and oxidative stress (54-56), and it also modulates $\mathrm{Ca}^{2+}$ release through the interaction with inositol 1,4,5-phosphate receptors (IP3R) (57). This modulation may underlie the anti-influenza effect of dextromethorphan, since viral transcription and replication require $\mathrm{Ca}^{2+}$ action through calmodulin $(20,58)$, and $\mathrm{Ca}^{2+}$ is also involved in viral entry through the regulation of clathrin-mediated and clathrinindependent endocytosis (59). If the primary mode of action of dextromethorphan-mediated $\sigma_{1}$-receptor signaling inhibition lies in such a direct inhibition of viral entry or replication, or rather in the modulation of innate immune responses (34) is the subject of ongoing studies.

Ferrets closely mimic the course of influenza disease seen in humans $(44,60)$. Seasonal and pandemic 2009 influenza viruses thus cause a mild to moderate disease of 3-5 days duration $(23,61)$, making it challenging to discern modest differences in disease severity and pathological and virological parameters. While oseltamivir reduced viral load and clinical disease, and prevented weight loss, dextromethorphan treatment only reduced disease severity, and seemed to slightly increase the weight loss compared to untreated animals. However, this seemingly small effect may make the difference between seeking medical attention or just staying at home, and may also reduce the days of lost productivity during the annual epidemics. Future studies are warranted to evaluate if combination treatment increases the efficacy of oseltamivir or other virus-targeting drugs, especially when treatment is started after the onset of clinical disease. There may also be room for short-term treatment at higher doses, given that the dosing regimen used here did not exceed recommended human weight-adjusted doses. Considering that dextromethorphan-containing drugs are frequently used as over the counter remedies for influenza and influenza-like respiratory infections, a more detailed evaluation of its efficacy, especially in combination with other influenzaspecific drugs, would be warranted.

\section{ETHICS STATEMENT}

This study was carried out in accordance with the recommendations of the SingHealth IACUC committee or the county experimental animal oversight agency (Regierungspraesidium Darmstadt), respectively.

\section{AUTHOR CONTRIBUTIONS}

TE performed most of the experiments. TE and VvM conceived the study, analyzed, and interpreted data, and wrote the manuscript. EG and DA designed and conducted the initial screening experiments. SS assisted with the in vitro and animal studies validating the top hits. DK and SM$S$ performed the bioinformatics analyses and wrote part of the manuscript.

\section{FUNDING}

This work was supported in part by funding from the German Center for Infection Research, the German Ministry of Health, and a DUKE-NUS Signature Research Program start-up grant funded by the Agency for Science, Technology, and Research (A*STAR), Singapore and the Ministry of Health, Singapore to VvM, and A*STAR grant H1699f0013 to SM-S.

\section{ACKNOWLEDGMENTS}

We thank all laboratory members for continuing support and lively discussions and Yvonne Krebs for excellent technical support. We would like to acknowledge Eugene Lim and Anne Baumgärtner for assistance with the titration experiments, Raphael Tze Chuen Lee for help with the co-expression, and Hong Sain Ooi for the protein-protein interaction data.

\section{SUPPLEMENTARY MATERIAL}

The Supplementary Material for this article can be found online at: https://www.frontiersin.org/articles/10.3389/fimmu. 2019.01097/full\#supplementary-material 


\section{REFERENCES}

1. Kilbourne ED. Influenza pandemics of the 20th century. Emerg Infect Dis. (2006) 12:9-14. doi: 10.3201/eid1201.051254

2. Osterhaus A, Brooks A, Broberg E, MacIntyre R, Capua I. Why should influenza be a public health priority. Vaccine. (2015) 33:7022-5. doi: 10.1016/j.vaccine.2015.08.049

3. Shaw ML and Palese P. Orthomyxoviridae. In: Knipe DM, Howley PM, editors. Fields Virology. Philadelphia, PA: Lippincott Williams \& Wilkins (2013). p. 1151-85.

4. Mehle A. Unusual influenza A viruses in bats. Viruses. (2014) 6:3438-49. doi: $10.3390 / \mathrm{v} 6093438$

5. Neumann G, Kawaoka Y. Transmission of influenza A viruses. Virology. (2015) 479-80:234-246. doi: 10.1016/j.virol.2015.03.009

6. Kalthoff D, Globig A, Beer M. Highly pathogenic avian influenza as a zoonotic agent. Vet Microbiol. (2010) 140:237-45. doi: 10.1016/j.vetmic.2009.08.022

7. Perdue ML, Swayne DE. Public health risk from avian influenza viruses. Avian Dis. (2005) 49:317-27. doi: 10.1637/7390-060305R.1

8. Wu H, Wang X, Xue M, Xue M, Wu C, Lu Q, et al. Spatial characteristics and the epidemiology of human infections with avian influenza A(H7N9) virus in five waves from 2013 to 2017 in Zhejiang Province, China. PLoS One. (2017) 12:e0180763. doi: 10.1371/journal.pone.0180763

9. Nafziger AN, Pratt DS. Seasonal influenza vaccination and technologies. J Clin Pharmacol. (2014) 54:719-31. doi: 10.1002/jcph.299

10. Intharathep $\mathrm{P}$, Laohpongspaisan $\mathrm{C}$, Rungrotmongkol $\mathrm{T}$, Loisruangsin A, Malaisree M, Decha P, et al. How amantadine and rimantadine inhibit proton transport in the M2 protein channel. J Mol Graph Model. (2008) 27:342-8. doi: 10.1016/j.jmgm.2008.06.002

11. Kamali A, Holodniy M. Influenza treatment and prophylaxis with neuraminidase inhibitors: a review. Infect Drug Resist. (2013) 6:187-98. doi: 10.2147/IDR.S36601

12. Deyde VM, Xu X, Bright RA, Shaw M, Smith CB, et al. Surveillance of resistance to adamantanes among influenza $\mathrm{A}(\mathrm{H} 3 \mathrm{~N} 2)$ and $\mathrm{A}(\mathrm{H} 1 \mathrm{~N} 1)$ viruses isolated worldwide. J Infect Dis. (2007) 196:249-57. doi: 10.1086/518936

13. Gubareva LV, Besselaar TG, Daniels RS, Fry A, Gregory V, Huang W, et al. Global update on the susceptibility of human influenza viruses to neuraminidase inhibitors, 2015-2016. Antiviral Res. (2017) 146:12-20. doi: 10.1016/j.antiviral.2017.08.004

14. Heo YA. Baloxavir: First global approval. Drugs. (2018) 78:693-7. doi: 10.1007/s40265-018-0899-1

15. Koszalka P, Tilmanis D, Hurt AC. Influenza antivirals currently in latephase clinical trial. Influenza Other Respir Viruses. (2017) 11:240-6. doi: 10.1111/irv.12446

16. de Chassey B, Meyniel-Schicklin L, Vonderscher J, André P, Lotteau V. Virus-host interactomics: new insights and opportunities for antiviral drug discovery. Genome Med. 6:115. doi: 10.1186/s13073-014-0115-1

17. Law GL, Korth MJ, Benecke AG, Katze MG. Systems virology: host-directed approaches to viral pathogenesis and drug targeting. Nat Rev Microbiol. (2013) 11:455-66. doi: 10.1038/nrmicro3036

18. Brass AL, Huang IC, Benita Y, John SP, Krishnan MN, Feeley EM, et al. The IFITM proteins mediate cellular resistance to influenza A H1N1 virus, West Nile virus, and dengue virus. Cell. (2009) 139:1243-54. doi: 10.1016/j.cell.2009.12.017

19. Karlas A, Machuy N, Shin Y, Pleissner KP, Artarini A, Heuer D, et al. Genomewide RNAi screen identifies human host factors crucial for influenza virus replication. Nature. (2010) 463:818-22. doi: 10.1038/nature08760

20. König R, Stertz S, Zhou Y, Inoue A, Hoffmann HH, Bhattacharyya S, et al. Human host factors required for influenza virus replication. Nature. (2010) 463:813-7. doi: 10.1038/nature08699

21. Shapira SD, Gat-Viks I, Shum BO, Dricot A, de Grace MM, Wu L, et al. A physical and regulatory map of host-influenza interactions reveals pathways in H1N1 infection. Cell. (2009) 139:1255-67. doi: 10.1016/j.cell.2009.12.018

22. Watanabe T, Watanabe S, Kawaoka Y. Cellular networks involved in the influenza virus life cycle. Cell Host Microbe. (2010) 7:427-39. doi: 10.1016/j.chom.2010.05.008

23. Svitek N, Rudd PA, Obojes K, Pillet S, von Messling V. Severe seasonal influenza in ferrets correlates with reduced interferon and increased IL-6 induction. Virology. (2008) 376:53-9. doi: 10.1016/j.virol.2008.02.035
24. Kobinger GP, Meunier I, Patel A, Pillet S, Gren J, Stebner S, et al. Assessment of the efficacy of commercially available and candidate vaccines against a pandemic H1N1 2009 virus. J Infect Dis. (2010) 201:1000-6. doi: $10.1086 / 651171$

25. Barrett T, Troup DB, Wilhite SE, Ledoux P, Rudnev D, Evangelista C, et al. NCBI GEO: mining tens of millions of expression profiles-database and tools update. Nucleic Acids Res. (2007) 35:D760-5. doi: 10.1093/nar/ gkl887

26. Ooi HS, Schneider G, Chan YL, Lim TT, Eisenhaber B, Eisenhaber F. Databases of protein-protein interactions and complexes. Methods Mol Biol. (2010) 609:145-59. doi: 10.1007/978-1-60327-241-4_9

27. Knox C, Law V, Jewison T, Liu P, Ly S, Frolkis A, et al. DrugBank 3.0: a comprehensive resource for "omics" research on drugs. Nucleic Acids Res. (2011) 39:D1035-41. doi: 10.1093/nar/gkq1126

28. Sleeman K, Mishin VP, Deyde VM, Furuta Y, Klimov AI, Gubareva LV. In vitro antiviral activity of favipiravir (T-705) against drug-resistant influenza and 2009 A(H1N1) viruses. Antimicrobial Agents Chemother. (2010) 54:2517-24. doi: 10.1128/AAC.01739-09

29. Tomie A, Azogu I, Yu L. Effects of naltrexone on post-abstinence alcohol drinking in C57BL/6NCRL and DBA/2J mice. Prog Neuropsychopharmacol Biol Psychiatry. (2013) 44:240-7. doi: 10.1016/j.pnpbp.2013.03.002

30. Apseloff G. Therapeutic uses of gallium nitrate: past, present, and future. Am J Ther. (1999) 6:327-39.

31. Bockman R. The effects of gallium nitrate on bone resorption. Semin Oncol. (2003) 30(2 Suppl. 5):5-12.

32. Yamauchi Y, Boukari H, Banerjee I, Sbalzarini IF, Horvath P, Helenius A. Histone deacetylase 8 is required for centrosome cohesion and influenza A virus entry. PLoS Pathog. (2011) 7:e1002316. doi: 10.1371/journal.ppat.1002316

33. Su TP, Su TC, Nakamura Y, Tsai SY. The Sigma-1 Receptor as a Pluripotent Modulator in Living Systems. Trends Pharmacol Sci. (2016) 37:262-78. doi: 10.1016/j.tips.2016.01.003

34. Martin WR, Eades CG, Thompson JA, Huppler RE, Gilbert PE. The effects of morphine- and nalorphine- like drugs in the nondependent and morphinedependent chronic spinal dog. J Pharmacol Exp Ther. (1976) 197:517-32.

35. Szabo A, Kovacs A, Frecska E, Rajnavolgyi E. Psychedelic N,Ndimethyltryptamine and 5-methoxy-N,N-dimethyltryptamine modulate innate and adaptive inflammatory responses through the sigma-1 receptor of human monocyte-derived dendritic cells. PLoS One. (2014) 9:e106533. doi: 10.1371/journal.pone.0106533

36. Bielory L, Lien KW, Bigelsen S. Efficacy and tolerability of newer antihistamines in the treatment of allergic conjunctivitis. Drugs. (2005) 65:215-28. doi: 10.2165/00003495-200565020-00004

37. Akkemik E, Budak H, Ciftci M. Effects of some drugs on human erythrocyte glucose 6-phosphate dehydrogenase: an in vitro study. J Enzyme Inhib Med Chem. (2010) 25:871-5. doi: 10.3109/14756360903489581

38. Janke R, Genzel Y, Wetzel M, Reichl U. Effect of influenza virus infection on key metabolic enzyme activities in MDCK cells. BMC Proc. (2011) 5(Suppl. 8):P129. doi: 10.1186/1753-6561-5-S8-P129

39. Hu Y, Jin Y, Han D, Zhang G, Cao S, Xie J, et al. Mast cell-induced lung injury in mice infected with H5N1 influenza virus. J Virol. (2012) 86:3347-56. doi: 10.1128/JVI.06053-11

40. Liu SL Li YH, Shi GY, Tang SH, Jiang SJ, Huang CW, Liu PY, et al. Dextromethorphan reduces oxidative stress and inhibits atherosclerosis and neointima formation in mice. Cardiovasc Res. (2009) 82:161-9. doi: $10.1093 / \mathrm{cvr} / \mathrm{cvp} 043$

41. Smee DF, Hurst BL, Wong MH, Bailey KW, Morrey JD. Effects of double combinations of amantadine, oseltamivir, and ribavirin on influenza A (H5N1) virus infections in cell culture and in mice. Antimicrob Agents Chemother. (2009) 53:2120-8. doi: 10.1128/AAC.01012-08

42. Nguyen L, Robson MJ, Healy JR, Scandinaro AL, Matsumoto RR. Involvement of sigma-1 receptors in the antidepressant-like effects of dextromethorphan. PLoS ONE. 9:e89985. doi: 10.1371/journal.pone.0089985

43. Bouvier NM. Animal models for influenza virus transmission studies: a historical perspective. Curr Opin Virol. (2015) 13:101-8. doi: 10.1016/j.coviro.2015.06.002

44. Enkirch T, von Messling V. Ferret models of viral pathogenesis. Virology. (2015) 479-480:259-70. doi: 10.1016/j.virol.2015.03.017 
45. Prussia A, Thepchatri P, Snyder JP, Plemper RK. Systematic approaches towards the development of host-directed antiviral therapeutics. Int J Mol Sci. (2011) 12:4027-52. doi: 10.3390/ijms12064027

46. Perwitasari O, Bakre A, Tompkins SM, Tripp RA. siRNA genome screening approaches to therapeutic drug repositioning. Pharmaceuticals. (2013) 6:12460. doi: 10.3390/ph6020124

47. Padhy BM, Gupta YK. Drug repositioning: re-investigating existing drugs for new therapeutic indications. J Postgrad Med. (2011) 57:153-60. doi: 10.4103/0022-3859.81870

48. Pollastri MP, Campbell RK. Target repurposing for neglected diseases. Future Med Chem. (2011) 3:1307-15. doi: 10.4155/fmc.11.92

49. Tripp RA, Mark Tompkins S. Antiviral effects of inhibiting host gene expression. Curr Top Microbiol Immunol. (2015) 386:459-77. doi: 10.1007/82_2014_409

50. Nurmatov UB, Rhatigan E, Simons FE, Sheikh A. H1 -antihistamines for primary mast cell activation syndromes: a systematic review. Allergy. (2015) 70:1052-61. doi: 10.1111/all.12672

51. Chung KF. Currently available cough suppressants for chronic cough. Lung. (2008) 186(Suppl 1):S82-7. doi: 10.1007/s00408-007-9030-1

52. Ryan T, Brewer M, Small L. Over-the-counter cough and cold medication use in young children. Pediatr Nurs. (2008) 34:174-80, 184.

53. Mori T, Hayashi T, Hayashi E, Su TP. Sigma-1 receptor chaperone at the ERmitochondrion interface mediates the mitochondrion-ER-nucleus signaling for cellular survival. PLoS ONE. 8:e76941. doi: 10.1371/journal.pone.0076941

54. Mitsuda T, Omi T, Tanimukai H, Sakagami Y, Tagami S, Okochi M, et al. Sigma-1Rs are upregulated via PERK/eIF2 $\alpha /$ ATF4 pathway and execute protective function in ER stress. Biochem Biophys Res Commun. (2011) 415:519-25. doi: 10.1016/j.bbrc.2011.10.113

55. Pal A, Fontanilla D, Gopalakrishnan A, Chae YK, Markley JL, Ruoho AE. The sigma-1 receptor protects against cellular oxidative stress and activates antioxidant response elements. Eur J Pharmacol. (2012) 682:12-20. doi: 10.1016/j.ejphar.2012.01.030
56. Vollrath JT, Sechi A, Dreser A, Katona I, Wiemuth D, Vervoorts J, et al. Loss of function of the ALS protein SigR1 leads to ER pathology associated with defective autophagy and lipid raft disturbances. Cell Death Dis. 5:e1290. doi: $10.1038 /$ cddis. 2014.243

57. Hayashi T, Su TP. Sigma-1 receptor chaperones at the ER-mitochondrion interface regulate $\mathrm{Ca}^{(2+)}$ signaling and cell survival. Cell. (2007) 131:596-610. doi: $10.1016 /$ j.cell.2007.08.036

58. Ochiai H, Kurokawa M, Niwayama S. Influence of trifluoperazine on the late stage of influenza virus infection in MDCK cells. Antiviral Res. (1991) 15:149-60. doi: 10.1016/ 0166-3542(91)90032-M

59. Fujioka Y, Tsuda M, Nanbo A, Hattori T, Sasaki J, Sasaki T, et al. A Ca ${ }^{(2+)}$. dependent signalling circuit regulates influenza A virus internalization and infection. Nat Commun. (2013) 4:2763. doi: 10.1038/ncomms3763

60. Belser JA, Katz JM, Tumpey TM. The ferret as a model organism to study influenza A virus infection. Dis Model Mech. (2011) 4:575-9. doi: 10.1242/dmm.007823

61. Watanabe T, Imai M, Watanabe S, Shinya K, Hatta M, Li C. Characterization in vitro and in vivo of pandemic (H1N1) 2009 influenza viruses isolated from patients. J Virol. (2012) 86:9361-8. doi: 10.1128/JVI.01214-12

Conflict of Interest Statement: The authors declare that the research was conducted in the absence of any commercial or financial relationships that could be construed as a potential conflict of interest.

Copyright (C) 2019 Enkirch, Sauber, Anderson, Gan, Kenanov, Maurer-Stroh and von Messling. This is an open-access article distributed under the terms of the Creative Commons Attribution License (CC BY). The use, distribution or reproduction in other forums is permitted, provided the original author(s) and the copyright owner(s) are credited and that the original publication in this journal is cited, in accordance with accepted academic practice. No use, distribution or reproduction is permitted which does not comply with these terms. 